\title{
Does Estrogen Affect the Development of Abnormal Vascular Function in Offspring of Rats Fed a Low-Protein Diet in Pregnancy?
}

\author{
YUKA MUSHA, SHIGERU ITOH, MARK A. HANSON, AND KATSUYUKI KINOSHITA
}

Department of Obstetrics and Gynecology [Y.M., S.I., K.K.], School of Medicine Juntendo University 2-1-1 Hongo, Bunkyo-ku Tokyo, Japan 113-8421; Centre for Developmental Origins of Health and Disease [M.A.H.], Princess Anne Hospital, University of Southampton, Southampton SO165YA, United Kingdom

\begin{abstract}
It is established that there are gender-related differences in the effects on offspring blood pressure induced by maternal protein restriction in animal studies. Since such effects may depend on estrogen levels, we hypothesized that lower estrogen would induce an earlier onset of hypertension caused by maternal undernutrition. Wistar rats were fed a diet containing either $18 \%(\mathrm{C})$ or $9 \%$ (R) casein throughout pregnancy. Half of the offspring in both $\mathrm{C}$ and $\mathrm{R}$ groups were ovariectomized on day 50 (CX, RX), and the other half underwent a sham operation (CO, RO). On d 175, offspring were killed for small artery reactivity and histologic investigation. Birth weight and later growth were not significantly different between $\mathrm{C}$ and R. RX had higher systolic blood pressure than CX on d125, but no difference was seen between RO and CO. On d 175, systolic blood pressure was higher in $\mathrm{R}$ than in $\mathrm{C}$, whether or not ovariectomized. Dilator responses to acetylcholine and bradykinin in small mesenteric arteries were significantly attenuated in RX, although responses to SNP and isoprenaline showed no attenuation in $\mathrm{R}$. The ratio of coronary peri-vascular fibrosis to total vascular area was higher in R, and the fibrosis became prominent in ovariectomized rats. These findings suggest that estrogen plays an important role in limiting the elevation of offspring blood pressure induced by maternal undernutrition, possibly via $\mathrm{BK}$-mediated mechanisms. The processes may underlie gender and life course patterns of hypertension and also the developmental origins of this disease. (Pediatr Res 59: 784-789, 2006)
\end{abstract}

$\mathrm{E}$ pidemiologic studies have shown an association between low birth weight and an increased incidence of cardiovascular, metabolic, and other diseases in later life (1-3). These human studies are strongly supported by animal studies. In the rat, a maternal low-protein diet or global under-nutrition in pregnancy often results in a reduction in birth weight, and produces an elevation in blood pressure or an impairment of glucose tolerance in adult offspring (4-6). The developmental origins of disease hypothesis propose that these cardiovascular and related disorders derive from fetal responses to maternal

Received September 7, 2005; accepted January 19, 2006.

Correspondence: Yuka Musha, M.D., Department of Obstetrics and Gynecology, School of Medicine, Juntendo University, Hongo 2-1-1, Bunkyo-ku Tokyo, Japan 113-8421; e-mail: yuka-m@med.juntendo.ac.jp

This study was supported by Grant-in-Aid for Scientific Research (Nos.16591080) from the Ministry of Education, Japan, to S. Itoh and Grant of Japanese Society for Child Nutrition Research to Y. Musha. Mark Hanson is supported by the British Heart Foundation. under-nutrition which permanently induce changes in the structure of tissues and organs, and in their physiologic control, in the offspring (7).

The mechanisms that underlie this effect are multi-factorial and complex. Mechanisms of hypertension and cardiovascular disease induced by maternal protein restriction include an alteration of the offspring's vascular function $(8-10)$, renal development (11), the renin-angiotensin system $(12,13)$, and the hypothalamic pituitary adrenal(HPA) axis (14). Examination of the underlying mechanisms should take into account the well-established gender-related differences in the occurrence of cardiovascular disease in humans at various ages (15). It is thus of interest that some animal studies have demonstrated that hypertension or vascular dysfunction induced by a maternal low-protein diet are more pronounced in males than in females $(8,16)$.

The sex hormone, estrogen, is known to modulate vascular tone and to protect the cardiovascular system (17-19), and it plays a role in vascular disease (20). However its role has not been investigated in the context of the developmental origins of disease. We therefore hypothesized that the effects of a low protein diet in inducing hypertension and vascular dysfunction in offspring would differ in offspring which were ovariectomized; in particular we hypothesized that, in the absence of the protective effect of estrogen in such animals, elevated blood pressure should develop more rapidly post-natally. This idea was tested in this study.

\section{METHODS}

The protocol for this study was approved by the animal experimental ethics committee of Juntendo University.

Animals and dietary protocols. Nine- to 12-wk-old virgin Female wistar rats (Sankyo Lab Service, Tokyo, Japan) were maintained at $23^{\circ} \mathrm{C}, 12 \mathrm{~L}: 12 \mathrm{D}$ cycles with free access to tap water and standard rat chow (laboratory animal diet MF; Oriental Yeast Co., Ltd., Tokyo, Japan). Female rats were mated

DOI: 10.1203/01.pdr.0000219126.78372.c8

Abbreviations: ACh, acetylcholine; BK, bradykinin; C, control diet, $18 \%$ casein; ISO, isoprenaline; KPSS, potassium PSS; O, ovary-intact sham operated; PE, phenylephrine; $\mathbf{p E \mathbf { C } _ { \mathbf { 5 0 } }}$, $\mathbf{- l o g}_{\mathbf{1 0}}$, effective concentration of agonist to achieve $50 \%$ of the maximum response; PSS, physiological salt solution; $\mathbf{R}$, protein-restricted diet, $9 \%$ casein; $\mathbf{S N P}$, sodium nitroprusside; $\mathbf{X}$, ovariectomized 
with male Wistar rats, and conception was confirmed by the observation of semen plugs on the floor of the mating cage. Pregnant rats were randomly divided into two dietary groups and were fed a control (C, 18\% casein) or low-protein (R, 9\% casein) diet throughout pregnancy. Five dams formed each group. The constituents of the iso-caloric experimental diets, described previously by Itoh et al. (21) are shown in Table 1. Just after the delivery of rat pups, the diet was replaced by standard chow. A day after delivery, pups were weighed, sexed and culled to six female pups per litter. Pups were weaned from their dams at $23 \mathrm{~d}$ of age. On day 50 , half of the offspring in both the $\mathrm{C}$ and $\mathrm{R}$ groups were ovariectomized (CX, RX), and the other half underwent a sham operation $(\mathrm{CO}, \mathrm{RO})$ while anaesthetized by inhalation of isoflurane. Vaginal smears were collected and cytology was analyzed to confirm the effectiveness of ovariectomy two to three weeks after the operation for several days. All offspring were weighed twice a week until the experimental day.

Blood pressure measurement. Blood pressure was measured indirectly with a tail-cuff apparatus (BP-98A; Softron, Japan) (22) at 50 (before operation), 75, 125 , and $175 \mathrm{~d}$ old as previously described by Langley-Evans et al. (23).

Terminal procedures. When 175 to 185 days old, the offspring were killed by $\mathrm{CO}_{2}$ inhalation and cervical dislocation at the diestrus phase of the estrus cycle, as indicated by cytology. Mesenteric arteries were dissected to assess vascular reactivity. Organs were weighed, and the hearts were analyzed histologically.

Organ weight measurements. At the postmortem examination, heart, lung, liver, spleen, kidneys, adrenal glands, and ovaries $(\mathrm{CO}, \mathrm{RO})$ were weighed.

Histology and morphometry. Hearts were fixed and stained with Azan stain for examination of histopathological changes in the coronary artery. Circular coronary arteries with a long-axis-to-short-axis ratio $<1.5$ were chosen as suitable cross sections. Peri-vascular fibrosis was assessed by calculating the ratio of the area of collagen-stained tissue to total vessel area. To evaluate arterial remodeling, the wall-area-to-lumen-area ratio was calculated. These analyses were performed with image-analyzing software KS400 (ver.3.0; ZEISS, Germany) by one investigator blinded to the animal treatment protocol.

Preparation of mesenteric arteries and normalization. The mesenteric arcade was excised and immediately immersed in ice-cold physiologic salt solution (PSS) (in $\mathrm{mM}: \mathrm{NaCl}, 119 ; \mathrm{KCl}, 4.7 ; \mathrm{CaCl}_{2}, 2.5 ; \mathrm{MgSO}_{4}, 1.17$; $\mathrm{NaHCO}_{3}, 25 ; \mathrm{KH}_{2} \mathrm{PO}_{4}, 1.18$; EDTA, 0.026; and glucose, 5.5). Small mesenteric arteries (diameter approximately $200 \mu \mathrm{m}$ ) were dissected free of connective tissue and were mounted in PSS on a wire myograph (Multi Myograph Model 610M; DMT A/S, Denmark) for the recording of isometric tension, as described previously by Itoh et al. (21) The passive tensioninternal circumference relationship $\left(\mathrm{IC}_{100}\right)$ was determined by incremental increases in tension to achieve an internal circumference equivalent to a transmural pressure of $100 \mathrm{~mm} \mathrm{Hg}$ (using the Laplace relationship) and the arteries were set to a diameter equivalent to $0.9 \times \mathrm{IC}_{100}$. Every two segments of mesenteric artery were dissected from a rat, and the average data were used for analysis.

Vascular reactivity. The experimental protocol was carried out in the order specified below. Vascular contraction to $125 \mathrm{mM}$ potassium PSS (KPSS) (125 $\mathrm{mM} \mathrm{K}$, an equimolar substitution of $\mathrm{NaCl}$ with $\mathrm{KCl}$ in PSS) and cumulative dose-responses to phenylephrine $(\mathrm{PE})\left(3 \times 10^{-8}\right.$ to $\left.1 \times 10^{-5}\right)$ and the thromboxane $\mathrm{A}_{2}$ mimetic, U46619 $\left(1 \times 10^{-9}\right.$ to $\left.3 \times 10^{-6}\right)$ were carried out under isometric conditions. The PE concentration used for pre-contraction was that required to produce $80 \%$ of the maximal response $\left(\mathrm{pEC}_{80}\right)$ induced by KPSS. Endothelium-dependent relaxation was assessed by acetylcholine (ACh)- $\left(1 \times 10^{-9}\right.$ to $\left.1 \times 10^{-6}\right)$ and bradykinin (BK)- $\left(1 \times 10^{-8}\right.$ to $\left.3 \times 10^{-6}\right)$ induced relaxation in PE-pre-contracted arteries. Endothelium-independent relaxation was determined by sodium nitroprusside (SNP) $\left(3 \times 10^{-8}\right.$ to $3 \times$ $\left.10^{-5}\right)$ and $\beta$-adrenergic relaxation by isoprenaline (ISO) $\left(1 \times 10^{-9}\right.$ to $3 \times$ $\left.10^{-6}\right)$.

Table 1. Composition of the $18 \%$ and $9 \%$ diets

\begin{tabular}{lcc}
\hline Component $(\mathrm{g} / 100 \mathrm{~g}$ diet $)$ & $18 \%$ casein diets & $9 \%$ casein diets \\
\hline Casein & 18.0 & 9.0 \\
Sucrose & 21.3 & 24.3 \\
Cellulose fiber & 5.0 & 5.0 \\
Cornstarch & 42.5 & 48.5 \\
Vitamin mix AIN-76 & 0.5 & 0.5 \\
Mineral mix AIN-76 & 2.0 & 2.0 \\
Maize oil & 10.0 & 10.0 \\
Choline chloride & 0.2 & 0.2 \\
Methionine & 0.5 & 0.5 \\
Magnesium sulfate & 0.05 & 0.05 \\
\hline
\end{tabular}

Dose-response curves were constructed by the addition of increasing concentrations at agonists at 2-min intervals, and $20 \mathrm{~min}$ was allowed between measurements of each response curve. All drugs and chemicals were obtained from Sigma Chemical Co.-Aldrich Japan K.K. (Tokyo, Japan).

Data analysis. Values are given as mean \pm SEM. Animal data and systolic blood pressure were compared by the Tukey Test (SPSS 11.5J, SPSS Inc., Chicago, IL). Tension of mesenteric artery is expressed as a percentage of maximal constriction to KPSS, to correct for any small differences in vessel diameter. Relaxation is expressed as a percentage of the initial preconstriction tension. The maximal values of the PE responses were calculated by least-squares nonlinear regression analysis, and the $\mathrm{pEC}_{50}$ was calculated (Prism 4.0, Graph Pad Software Inc., San Diego, CA, U.S.A.) if appropriate. These values were compared by the Tukey Test. If a calculation of $\mathrm{pEC}_{50}$ was not appropriate, due to the shape of the response curve, concentrationresponse curves were compared by two-way repeated measures ANOVA (Prism 4.0, Graph Pad Software Inc.). Significance was assumed if $p<0.05$.

\section{RESULTS}

Animal data. There was no significant difference in birth weight (C: $5.34 \pm 0.2, n=20, \mathrm{R}: 5.10 \pm 0.2 \mathrm{~g}, n=22$ ) or mean litter size (C: $9.4 \pm 0.6, \mathrm{R}: 10.8 \pm 1.4$ ) between $\mathrm{C}$ and $\mathrm{R}$. The number of female pups in each dam which were chosen for the present study was not significant between both groups (average; C: $4.0 \pm 0.4, \mathrm{R}: 4.6 \pm 0.4$ ). After being ovariectomized at $50 \mathrm{~d}$ of age, $\mathrm{CX}, \mathrm{RX}$ gained significantly more weight than sham-operated offspring (CO, RO), although this change was not influenced by maternal diet (Fig. 1).

Individual organ weights are measured, but there were no differences in weight in the hearts, livers, kidneys, spleens, lungs, adrenal glands, and ovaries (data not shown).

The day of the terminal procedure were day $181.1 \pm 1.7$ (CO), $179.8 \pm 1.2(\mathrm{CX}), 178.4 \pm 1.4(\mathrm{RO}), 179.1 \pm 1.4(\mathrm{RX})$, respectively. There were no significant differences in the day of experiment among all groups.

Blood pressure measurement. Systolic blood pressures in the 50-day-old offspring were similar among the groups (Table 2). However, after d 75, blood pressure tended to increase in group R, and this was prominent in RX. On d 125, RX showed significantly higher systolic blood pressure than $\mathrm{CX}(p=0.001)$, although it was not significantly higher in RO than CO. On d 175, offspring in the R groups showed signif-

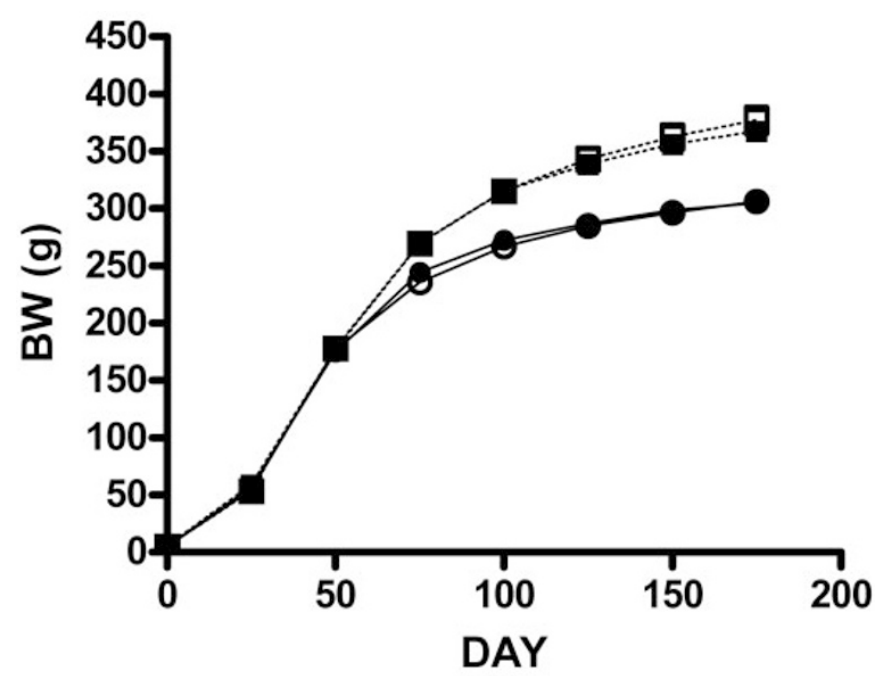

Figure 1. Body weight of offspring in $\mathrm{CO}(\boldsymbol{\bullet}, n=9), \mathrm{CX}(\boldsymbol{\square}, n=11)$, RO $(\bigcirc, n=11)$, and $\mathrm{RX}(\square, n=11)$. 
Table 2. Systolic blood pressure ( $\mathrm{mm} \mathrm{Hg}$ ) in offspring

\begin{tabular}{lcccc}
\hline & CO & CX & RO & RX \\
\hline Day 50 & $108.7 \pm 2.5(9)$ & $109.4 \pm 3.3(11)$ & $114.4 \pm 2.2(11)$ & $113.4 \pm 2.2(11)$ \\
Day 75 & $112.0 \pm 1.5(9)$ & $113.0 \pm 2.2(11)$ & $117.6 \pm 1.8(11)$ & $119.7 \pm 2.1(11)^{*}$ \\
Day 125 & $109.8 \pm 1.1(8)$ & $111.1 \pm 1.8(11)$ & $116.4 \pm 1.3(11)$ & $120.9 \pm 2.4(11)^{* *} \S$ \\
Day 175 & $105.7 \pm 2.0(9)$ & $109.3 \pm 1.4(11)$ & $118.5 \pm 2.3(11)^{* *}$ & $122.5 \pm 2.3(11)^{* *} \S$ \\
\hline
\end{tabular}

Values are given as mean \pm SEM.

$* p<0.05$ versus $\mathrm{CO} ; * * p<0.001$ versus $\mathrm{CO} ; \S p<0.001$ versus $\mathrm{CX}$.

$\mathrm{C}$, control; O, ovary-intact sham operated; R, protein-restricted; X, ovariectomized.

(n), number of observations.

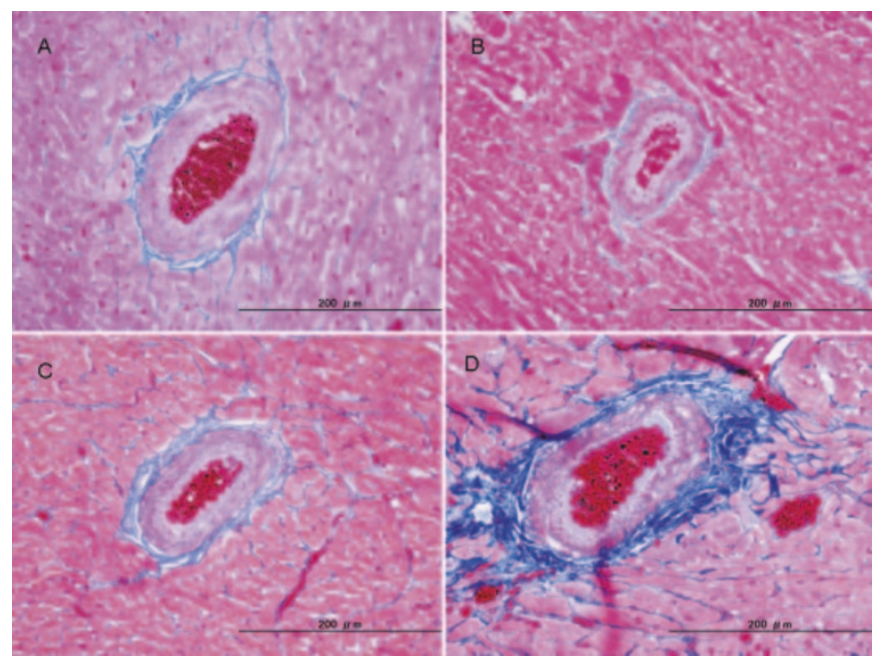

Figure 2. Collagen deposition, demonstrated by Azan staining, in the perivascular regions of the coronary arteries on $\mathrm{d} 175$ in $\mathrm{CO}(\mathrm{A}), \mathrm{CX}(\mathrm{B}), \mathrm{RO}(\mathrm{C})$, RX (D). Augmented peri-vascular fibrosis is apparent in RX.

icantly higher blood pressure than those in $\mathrm{C}$, regardless of the presence of ovaries ( $\mathrm{RX}$ versus $\mathrm{CX}: p=0.000$, RO versus CO: $p=0.001$ ).

Histology and morphometry. The ratio of coronary perivascular fibrous tissue to total vascular area was higher in the $\mathrm{R}$ groups than $\mathrm{C}$, and the fibrosis became prominent in ovariectomized rats (Fig. 2). On the other hand, all groups showed comparable arterial wall thickness (Table 3).

Vascular responses. Data for arterial size and vascular function in the isolated arteries are shown in Table 4. The normalized internal diameters were found to be similar in each group.

Contractile responses. The maximal contraction induced by KPSS was attenuated in RO compared with $\mathrm{CO}(p<0.05)$. $\mathrm{PE}$ and U46619 produced a concentration-dependent contraction of mesenteric arteries in each group. There were no significant differences in the PE and U46619 dose-response curves among the groups (Fig. 3).

Relaxant responses. ACh produced a concentrationdependent relaxation of PE-constricted arteries in each group. The maximal relaxation to ACh $\left(1 \times 10^{-6}\right)$ was reduced in RX versus RO $(p<0.05)$. BK, SNP, and ISO also caused a concentration-dependent relaxation of PE-constricted arteries in each group. The maximal relaxation in response to $\mathrm{BK}(3 \times$ $\left.10^{-7}: \mathrm{CO}, \mathrm{CX}, \mathrm{RO} ; 5 \times 10^{-7}: \mathrm{RX}\right), \mathrm{SNP}\left(3 \times 10^{-5}\right)$, and ISO $\left(1 \times 10^{-6}: \mathrm{CO}, \mathrm{CX}, \mathrm{RO} ; 3 \times 10^{-7}: \mathrm{RX}\right)$ was not different among the groups. However, the overall relaxant response to
BK ( $p<0.05$, two-way ANOVA) was significantly less in RX than RO $(p=0.009)$, and $\mathrm{CX}(p=0.001)$, although $\mathrm{CX}$ was not blunted compared with CO (Figs. 4, 5). There were no significant differences among each group in the responses to SNP and ISO.

\section{DISCUSSION}

In the present study, we demonstrated that a maternal low-protein diet throughout pregnancy induces increased systolic blood pressure in female Wistar rat offspring, as previously reported (8) although it did not produce either intrauterine growth restriction or accelerated catch-up growth in offspring. Evidence from epidemiologic studies suggests that low birth weight or disproportionality (thin or short) at birth is associated with high rates of diseases such as hypertension, coronary heart disease, and non-insulin-dependent diabetes mellitus in adulthood (1-3). Offspring of animals exposed to restricted nutrition in pregnancy show elevated blood pressure (8), glucose intolerance, and insulin resistance $(24,25)$, but these studies show various effects on birth weights of offspring. In some, protein restriction led to intrauterine growth restriction $(9,16,25)$, but in others no change was reported $(10,26,27)$. This may be due to differences in the composition of the diet, i.e., the ratio of protein to total caloric content, and the period of pregnancy. Offspring of dams exposed to global caloric restriction are generally born with low birth weight $(8,28)$. The absence of consistent effects on size at birth following prenatal challenges which reliably produce physiologic changes in offspring reinforces the idea that birth weight is a crude proxy measure of fetal developmental responses (7).

Although ovariectomized rats (CX, RX) gained more weight after surgery than sham-operated controls (CO, RO), the pattern of growth was very similar in $\mathrm{C}$ and $\mathrm{R}$. It is known that ovariectomy increases food consumption and body mass (29), but a detailed mechanism for the increase in body weight gain in response to ovariectomy remains unknown (30). As $\mathrm{RX}$ rats did not show notable weight gain compared with CX, it may be that the prominent hypertension in RX was not caused only by accelerated weight gain.

Ozaki et al. have shown that maternal under-nutrition induces hypertension in male offspring at a younger age than in female offspring (8). Franco et al. have shown that the severity of the hypertension is greater in male offspring (16). We can therefore infer that gender differences in hypertension caused by maternal dietary deprivation might be related to sex hormones. It has been reported that serum estrogen levels in rats exposed to intrauterine under-nutrition are only half those of 
Table 3. Morphometry of coronary arteries

\begin{tabular}{|c|c|c|c|c|}
\hline & $\mathrm{CO}(n=7)$ & $\mathrm{CX}(n=10)$ & $\mathrm{RO}(n=10)$ & $\mathrm{RX}(n=10)$ \\
\hline Peri-vascular fibrosis index & $23.56 \pm 1.19$ & $22.38 \pm 1.61$ & $27.85 \pm 1.77$ & $30.98 \pm 2.50 *$ \\
\hline Arterial thickening index & $40.57 \pm 14.06$ & $38.20 \pm 12.47$ & $36.90 \pm 12.30$ & $38.00 \pm 11.90$ \\
\hline
\end{tabular}

Peri-vascular fibrosis index $=$ area of collagen-stained fibrosis to total vessel area (\%).

Arterial thickening index $=$ arterial wall area to lumen area $(\%)$.

$* p<0.05$ versus $\mathrm{CX}$.

$\mathrm{C}$, control; O, ovary-intact sham operated; R, protein-restricted; X, ovariectomized.

Table 4. Vascular function of the mesenteric arteries in offspring

\begin{tabular}{|c|c|c|c|c|}
\hline & $\mathrm{CO}$ & $\mathrm{CX}$ & RO & $\mathrm{RX}$ \\
\hline Lumen diameter $(\mu \mathrm{m})$ & $226.52 \pm 7.77(8)$ & $216.82 \pm 7.60(11)$ & $204.03 \pm 3.92(10)$ & $213.99 \pm 5.70(11)$ \\
\hline \multicolumn{5}{|l|}{ Maximal contraction } \\
\hline 125 mM KPSS (mN/mm) & $5.32 \pm 0.28(8)$ & $5.02 \pm 0.18(11)$ & $4.39 \pm 0.22(10)^{*}$ & $5.02 \pm 0.22(11)$ \\
\hline U46619 (\% 125 mM KPSS $)$ & $104.02 \pm 1.85(8)$ & $98.25 \pm 5.12(11)$ & $101.67 \pm 1.51(9)$ & $99.96 \pm 1.26(11)$ \\
\hline \multicolumn{5}{|l|}{ Maximal relaxation $(\%)$} \\
\hline Acetylcholine & $96.67 \pm 0.53(7)$ & $97.13 \pm 0.79(10)$ & $97.89 \pm 0.36(10)$ & $95.58 \pm 0.68(11) \S$ \\
\hline SNP & $93.43 \pm 0.89(8)$ & $81.49 \pm 3.83(10)$ & $85.09 \pm 5.98(9)$ & $85.17 \pm 2.29$ \\
\hline \multicolumn{5}{|l|}{$\mathrm{pEC}_{50}(-\log \mathrm{M})$} \\
\hline Phenylephrine & $6.38 \pm 0.16(7)$ & $6.55 \pm 0.09(10)$ & $6.38 \pm 0.08(10)$ & $6.55 \pm 0.08(11)$ \\
\hline U46619 & $7.44 \pm 0.12(8)$ & $7.33 \pm 0.12(11)$ & $7.14 \pm 0.09(9)$ & $7.31 \pm 0.09(11)$ \\
\hline Acetylcholine & $7.59 \pm 0.12(7)$ & $7.57 \pm 0.08(10)$ & $7.67 \pm 0.10(10)$ & $7.53 \pm 0.07(11)$ \\
\hline Isoprenaline & $6.54 \pm 0.79(8)$ & $7.19 \pm 0.08(10)$ & $7.39 \pm 0.11(9)$ & $7.30 \pm 0.04$ \\
\hline
\end{tabular}

Values are given as mean \pm SEM.

$* p<0.05$ versus $\mathrm{CO} ; \S p<0.05$ versus $\mathrm{RO}$.

$\mathrm{N} / \mathrm{A}$, calculation of $\mathrm{pEC}_{50}$ was not appropriate.

(n), number of observations.

controls (16). In the present study, ovariectomy caused significantly earlier elevation of systolic blood pressure in offspring of $\mathrm{R}$ dams. Therefore, estrogen may limit the elevated blood pressure observed in offspring of nutritionally restricted dams.

It has been shown that intrauterine nutritional deficiency leads to permanent alteration of offspring vascular structure and function (31). As in previous studies, we studied mesenteric arteries because they play an important role in the control of peripheral vascular resistance (32). We found that the contractile response to KPSS was reduced only in RO, but that ovariectomy did not affect this attenuation. The lumen diameter of mesenteric arteries of RO was slightly smaller than the other groups although it did not reach statistical difference. In previous reports $(8,33)$, smaller lumen diameter was associated with smaller maximal contraction to KPSS. However in the present study we did not carry out cumulative doseresponse to potassium, so we cannot determine whether this was the mechanism underlying the effect.

Maximal relaxation induced by ACh was decreased in RX, but CX did not differ from CO. Previous studies have demonstrated an attenuated response to $\mathrm{ACh}$ in the mesenteric arteries of female rats exposed to intrauterine under-nutrition $(16,28)$. This difference merits further consideration because, although both ACh and BK are endothelium-dependent vasodilators and important contributors to hypertension, there are some differences between the two. In a previous study of spontaneously hypertensive rats (SHR), ACh-induced relaxation of mesenteric arteries was preserved, or even slightly improved, in young (7 wk) and adult (21 wk) rats, but was finally impaired in old rats (51 wk), although BK-induced relaxation was impaired at all ages (34). These results suggest that impairment of $\mathrm{ACh}$-induced endothelium-dependent vasorelaxation in the mesenteric vascular bed of SHR is a secondary phenomenon, perhaps following the prolonged influence of hypertension, while the impaired BK-induced vasorelaxation is a primary change which may be closely related to the development of hypertension.

Vasodilation to BK in mesenteric arteries is mediated primarily by production of NO through the stimulation of BK subtype 2 receptors $\left(B_{2} R s\right)$. However, when NO synthesis is reduced, $\mathrm{ACh}$ maintains endothelial vasodilator function in mesenteric arteries through activation of endothelium-derived hyperpolarizing factor (10). These differences in the method of dilation could be explained by the reduced eNOS activity (16) and enhanced oxidative stress (9) following intrauterine undernutrition. Indeed, in a previous study (8), the femoral arteries of rat offspring of nutritionally restricted dams showed no attenuation of vasodilatation to $\mathrm{ACh}$, as here for the mesenteric bed.

The endothelium-dependent relaxant response to BK was blunted in offspring of dams fed a maternal low-protein diet. In addition, a blunted response to BK was more prominent in $\mathrm{RX}$, whereas the effect of ovariectomy was less in CX. It 
A

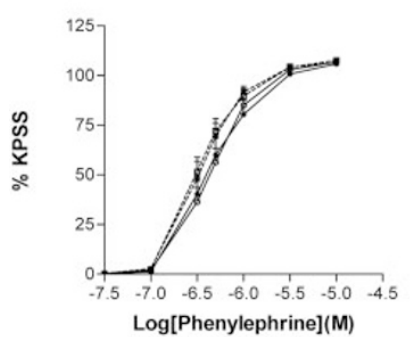

B

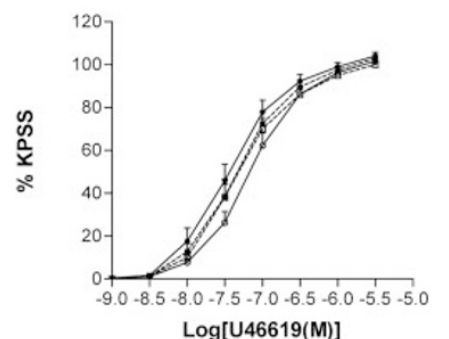

Figure 3. A) Vascular contraction in response to phenylephrine in mesenteric arteries from female offspring aged d 175 in $\mathrm{CO}(\bullet, n=7), \mathrm{CX}(\boldsymbol{\square}, n=10)$, $\mathrm{RO}(\mathrm{O}, n=10)$, RX ( $\square, n=11)$. B, vascular contraction to U46619 in mesenteric arteries from female offspring aged d 175 in $\mathrm{CO}(\bullet, n=8), \mathrm{CX}$ $(\boldsymbol{\square}, n=11)$, RO (O, $n=9), \mathrm{RX}(\square, n=11)$.
A

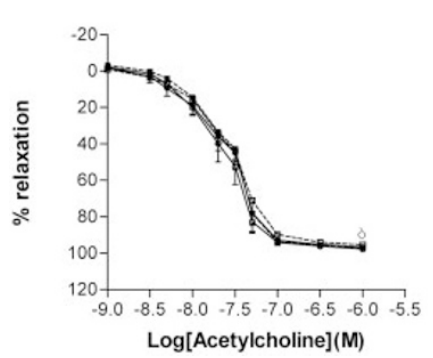

B

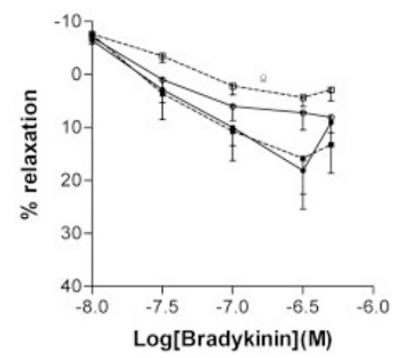

Figure 4. A) Vascular relaxation in response to acetylcholine in mesenteric arteries from female offspring aged d 175 in $\mathrm{CO}(\boldsymbol{\bullet}, n=7), \mathrm{CX}(\boldsymbol{\square}, n=10)$, $\mathrm{RO}(\mathrm{O}, n=10)$, RX ( $\square, n=11) ; * p<0.05 \mathrm{RX}$ versus $\mathrm{RO}$ maximum relaxation (Tukey test). B) Vascular relaxation in response to bradykinin in mesenteric arteries from female offspring aged d 175 in $\mathrm{CO}(\bullet, n=8), \mathrm{CX}$ $(\boldsymbol{\square}, n=11), \mathrm{RO}(\bigcirc, n=9), \mathrm{RX}(\square, n=11) ; \S p<0.05 \mathrm{RX}$ versus $>\mathrm{CX}$ and $\mathrm{RX}$ versus $\mathrm{CX}$ overall relaxation via two-way ANOVA.
A

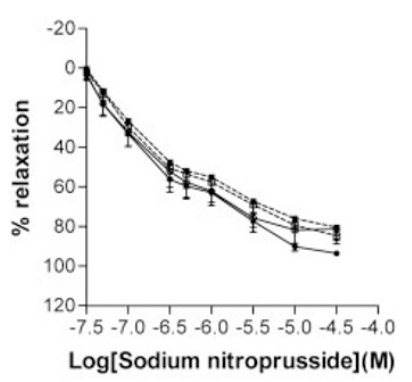

B

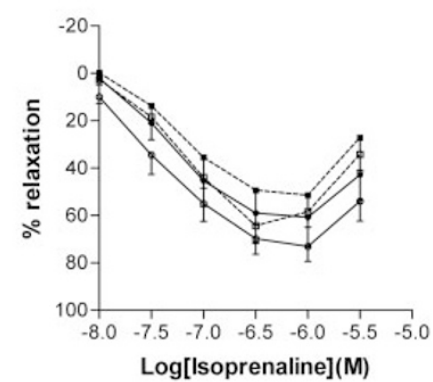

Figure 5. A) vascular relaxation in response to SNP in mesenteric arteries from female offspring aged d 175 in $\mathrm{CO}(\bullet, n=8), \mathrm{CX}(\boldsymbol{\square}, n=10), \mathrm{RO}(\bigcirc$, $n=9), \operatorname{RX}(\square, n=11)$. B) Vascular relaxation in response to isoprenaline in mesenteric arteries from female offspring aged d 175 in $\mathrm{CO}(\bullet, n=8), \mathrm{CX}$ $(\boldsymbol{\square}, n=11), \mathrm{RO}(\bigcirc, n=9), \mathrm{RX}(\square, n=11)$.

therefore appears that vasoreactivity to BK is worsened by estrogen depletion. Estrogen affects coronary arteries as it does other arterial beds (35). Moreover, it down-regulates ACE with a consequent decrease in the metabolism of bradykinin (36). Therefore, in offspring of dietary restricted dams, it is likely that disturbances of BK-mediated pathways play a more important role than those mediated by $\mathrm{ACh}$, not only in the development of hypertension but also in creating gender differences, because of the close interaction with estrogen.

In the present study, vasorelaxation to SNP was not blunted by either maternal under-nutrition or ovariectomy. It seems that the reactivity of smooth muscle to NO was therefore not impaired by a maternal low-protein diet. It is known that isoprenaline induced vasodilatation not only by the direct action on smooth muscle cells but also by stimulating endothelial $\beta_{2}$-adorenoceptors resulting in elevation basal nitric oxide release via a cAMP-dependent mechanism on the endothelium $(37,38)$. But according to some papers, these responses are different depend on vessels or endocrine environment $(38,39)$. In the present study, therefore, we assessed the influence of maternal low-protein diet to $\beta_{2}$-adrenoceptors. ISO dilated mesenteric arteries similarly in all groups, suggesting that the function of this receptor was not impaired by maternal protein restriction.

Modulation of peri-vascular fibrous tissue content is closely related to the kallikrein-kinin system. BK released from cardiomyocytes through angiotensinII type 2 receptor $\left(\mathrm{AT}_{2} \mathrm{R}\right)$ signaling activates endothelial $\mathrm{B}_{2} \mathrm{Rs}$, leading to activation of eNOS and NO-dependent inhibition of peri-vascular fibrosis (40). In the present study, we found that the peri-vascular fibrosis of coronary arteries was more severe in R, especially in RX. Estrogen is best known to have an indirect cardioprotective effect by modulating lipoprotein metabolism $(41,42)$. However recently, a direct effect of estrogen on the heart has been reported in the rat via down-regulation of ACE, with consequent reduction of Ang II-mediated vasoconstriction and an increase in BK in the heart (36).

Estrogen induces relaxation of coronary arteries in the rat heart (19). Although we did not measure coronary artery responses, a previous study has shown that coronary arterial tone responses to $\mathrm{BK}$ are less in ovariectomized compared with intact rats (35). Taken together, our results indicate that maternal under-nutrition attenuates vasodilator responses to BK. This may cause peri-vascular fibrosis in coronary arteries. These effects are exacerbated by low estrogen levels. Lower levels of estrogen induced by maternal dietary imbalance $(16,36)$ may thus predispose to higher levels of coronary artery fibrosis as well as hypertension. This relationship between estrogen and BK levels could explain the higher risk of cardiovascular disease in males than in females, and in postmenopausal women than in young women (43).

In summary, a maternal low-protein diet during pregnancy induces hypertension in rat offspring without intrauterine growth restriction. In addition, ovariectomized rats develop hypertension earlier than do intact animals. Offspring of low protein fed dams show attenuated vasorelaxation to BK, and again the effect was made worse by ovariectomy. Because BK has cardioprotective effects on the heart in conjunction with estrogen our results suggest that perturbation of this mechanism may be fundamental to the aetiology of hypertension, not only to its pattern of occurrence in relation to gender and age, but also in the developmental origins of this disease.

Acknowledgments. The authors would like to thank Prof. Kazuhisa Ishi belonging to the Department of Pathology, 
Juntendo University Urayasu Hospital, for his expert support in histopathology and morphometry.

\section{REFERENCES}

1. Barker DJ, Bull AR, Osmond C, Simmonds SJ 1990 Fetal and placental size and risk of hypertension in adult life. BMJ 301:259-262

2. Barker DJ 1994 Mothers, babies and disease in later life. BMJ Publishing, London

3. Phillips DI, Barker DJ, Hales CN, Hirst S, Osmond C 1994 Thinness at birth and insulin resistance in adult life. Diabetologia 37:150-154

4. Langley SC, Jackson AA 1994 Increased systolic blood pressure in adult rats induced by fetal exposure to maternal low protein diets. Clin Sci 86:217-222

5. Hales CN 1997 Fetal and infant growth and impaired glucose tolerance in adulthood: the "thrifty phenotype" hypothesis revisited. Acta Paediatr Suppl 442:73-77

6. Ozanne SE, Wang CL, Dorling MW, Petry CJ 1999 Dissection of the metabolic actions of insulin in adipocytes from early growth-retarded male rats. J Endocrinol 162:313-319

7. Gluckman PD, Hanson MA 2004 Living with the past: evolution, development, and patterns of disease. Science 305:1733-1736

8. Ozaki T, Nishina H, Hanson MA, Poston L 2001 Dietary restriction in pregnant rats causes gender-related hypertension and vascular dysfunction in offspring. J Physiol 530:141-152

9. Franco Mdo C, Dantas AP, Akamine EH, Kawamoto EM, Fortes ZB, Scavone C, Tostes RC, Carvalho MH, Nigro D 2002 Enhanced oxidative stress as a potential mechanism underlying the programming of hypertension in utero. J Cardiovasc Pharmacol 40:501-509

10. Brawley L, Itoh S, Torrens C, Barker A, Bertram C, Poston L, Hanson M 2003 Dietary protein restriction in pregnancy induces hypertension and vascular defects in rat male offspring. Pediatr Res 54:83-90

11. Law CM, de Swiet M, Osmond C, Fayers PM, Barker DJ, Cruddas AM, Fall CH 1993 Initiation of hypertension in utero and its amplification throughout life. BMJ 306:24-27

12. Langley-Evans SC, Jackson AA 1995 Captopril normalizes systolic blood pressure in rats with hypertension induced by fetal exposure to maternal low protein diets. Comp Biochem Physiol A Physiol 110:223-228

13. Sherman RC, Langley-Evans SC 1998 Early administration of angiotensinconverting enzyme inhibitor captopril, prevents the development of hypertension programmed by intrauterine exposure to a maternal low-protein diet in the rat. Clin Sci 94:373-381

14. Gardner DS, Jackson AA, Langley-Evans SC 1997 Maintenance of maternal dietinduced hypertension in the rat is dependent on glucocorticoids. Hypertension 30:1525-1530

15. Pechere-Bertschi A, Burnier M 2004 Female sex hormones, salt, and blood pressure regulation. Am J Hypertens 17:994-1001

16. Franco Mdo C, Arruda RM, Dantas AP, Kawamoto EM, Fortes ZB, Scavone C, Carvalho MH, Tostes RC, Nigro D 2002 Intrauterine under-nutrition: expression and activity of the endothelial nitric oxide synthase in male and female adult offspring. Cardiovasc Res 56:145-153

17. Adams MR, Clarkson TB, Kaplan JR, Koritnik DR 1989 Experimental evidence in monkeys for beneficial effects of estrogen on coronary artery atherosclerosis. Transplant Proc 21:3662-3664

18. Sudoh N, Toba K, Akishita M, Ako J, Hashimoto M, Iijima K, Kim S, Liang YQ, Ohike Y, Watanabe T, Yamazaki I, Yoshizumi M, Eto M, Ouchi Y 2001 Estrogen prevents oxidative stress-induced endotherial cell apoptosis in rats. Circulation 103:724-729

19. Santos RL, Abreu GR, Bissoli NS, Moyses MR 2004 Endothelial mediators of $17 \beta$-estradiol-induced coronary vasodilation in the isolated rat heart. Braz J Med Biol Res 37:569-575

20. Zhu Y, Bian Z, Lu P, Karas RH, Bao L, Cox D, Hodgin J, Shaul PW, Thoren P, Smithies O, Gustafsson JA, Mendelsohn ME 2002 Abnormal vascular function and hypertension in mice deficient in estrogen receptor $\beta$. Science 295:505-508

21. Itoh S, Brawley L, Wheeler T, Anthony FW, Poston L, Hanson MA 2002 Vasodilation to vascular endothelial growth factor in the uterine artery of the pregnant rat is blunted by low dietary protein intake. Pediatr Res 51:485-491
22. Kuwahara M, Sugano S, Yayou K, Tsubone H, Kobayashi H 1991 Evaluation of a new tail-cuff method for blood pressure measurement in rats with special reference to the effects of ambient temperature. Jikken Dobutsu 40:331-336

23. Langley-Evans SC, Welham SJ, Sherman RC, Jackson AA 1996 Weanling rats exposed to maternal low-protein diets during discrete periods of gestation exhibit differing severity of hypertension. Clin Sci (Lond) 91:607-615

24. Langley-Evans SC 1997 Intrauterine programming of hypertension by glucocorticoids. Life Sci 60:1213-1221

25. Fernandez-Twinn DS, Ozanne SE, Ekizoglou S, Doherty C, James L, Gusterson B, Hales CN 2003 The maternal endocrine environment in the low-protein model of intra-uterine growth restriction Br J Nutr;90:815-822

26. Langley-Evans SC, Gardner DS, Jackson AA 1996 Association of disproportionate growth of fetal rats in late gestation with raised systolic blood pressure in later life. J Reprod Fertil 106:307-312

27. Kwong WY, Wild AE, Roberts P, Willis AC, Fleming TP 2000 Maternal under-nutrition during the preimplantation period of rat development causes blastocyst abnormalities and programming of postnatal hypertension. Development 127:4195-4202

28. Holemans K, Gerber R, Meurrens K, De Clerck, F Poston L, Van Assche FA 1999 Maternal food restriction in the second half of pregnancy affects vascular function but not blood pressure of rat female offspring. Br J Nutr 81:73-79

29. McElroy JF, Wade GN 1987 Short- and long-term effects of ovariectomy on food intake, body weight, carcass composition, and brown adipose tissue in rats. Physiol Behav 39:361-365

30. Chen Y, Heiman ML 2001 Increased weight gain after ovariectomy is not a consequence of leptin resistance. Am J Physiol Endocrinol Metab 280:E315-E322

31. Barker DJ 1997 Fetal nutrition and cardiovascular disease in later life. Br Med Bull 53:96-108

32. Christensen KL, Mulvany MJ 1993 Mesenteric arcade arteries contribute substantially to vascular resistance in conscious rats. J Vasc Res 30:73-79

33. Nishina H, Green LR, McGarrigle HH, Noakes DE, Poston L, Hanson MA 2003 Effect of nutritional restriction in early pregnancy on isolated femoral artery function in mid-gestation fetal sheep. J Physiol 553:637-647

34. Wirth KJ, Linz W, Wiemer G, Scholkens BA 1996 Differences in acetylcholine- and bradykinin-induced vasorelaxation of the mesenteric vascular bed in spontaneously hypertensive rats of different ages. Naunyn Schmiedebergs Arch Pharmacol 354:38-43

35. Mericli M, Nadasy GL, Szekeres M, Varbiro S, Vajo Z, Matrai M, Acs N, Monos E, Szekacs B 2004 Estrogen replacement therapy reverses changes in intramural coronary resistance arteries caused by female sex hormone depletion. Cardiovasc Res 61:317-324

36. Gallagher PE, Li P, Lenhart JR, Chappell MC, Brosnihan KB 1999 Estrogen regulation of angiotensin-converting enzyme mRNA. Hypertension 33:323-328

37. Schlaich MP, Ahlers BA, Parnell MM, Kaye DM 2004 beta- Adrenoceptormediated, nitric-oxide-dependent vasodilatation is abnormal in early hypertension: restoration by L-arginine. J Hypertens 22:1917-1925

38. Chan HY, Yao X, Tsang SY, Bourreau JP, Chan FL, Huang Y 2002 Isoproterenol amplifies 17 beta-estradiol-mediated vasorelaxation: role of endothelium/ nitric oxide and cyclic AMP. Cardiovasc Res 53:627-633

39. Longo M, Jain V, Vedernikov YP, Bukowski R, Garfield RE, Hankins GD, Anderson GD, Saade GR 2005 Fetal origins of adult vascular dysfunction in mice lacking endothelial nitric oxide synthase. Am J Physiol Regul Integr Comp Physiol 288:R1114-R1121

40. Kurisu S, Ozono R, Oshima T, Kambe M, Ishida T, Sugino H, Matsuura H, Chayama K, Teranishi Y, Iba O, Amano K, Matsubara H 2003 Cardiac angiotensin II type 2 receptor activates the kinin/NO system and inhibits fibrosis. Hypertension 41:99-107

41. Barrett-Connor E, Bush TL 1991 Estrogen and coronary heart disease in women JAMA 256:1861-1867

42. Stampfer MJ, Colditz GA 1991 Estrogen replacement therapy and coronary heart disease: a quantitative assessment of the epidemiologic evidence. Prev Med 20:47-63

43. Castelli WP 1988 Cardiovascular disease in women. Am J Obstet Gynecol 158:1553-1560 